\title{
Pozzolanic Effect on the Hydration Heat of Cements Incorporating Fly Ash, Obsidian, and Slag Additives
}

\author{
Ilker Ustabas $\mathbb{D}^{1},{ }^{1}$ Sakir Erdogdu, ${ }^{2}$ Ihsan Omur, ${ }^{1}$ and Erol Yilmaz $\mathbb{D}^{1}$ \\ ${ }^{1}$ Department of Civil Engineering, Faculty of Engineering and Architecture, Recep Tayyip Erdogan University, \\ Rize TR53100, Turkey \\ ${ }^{2}$ Department of Civil Engineering, Faculty of Engineering, Karadeniz Technical University, Trabzon TR61080, Turkey \\ Correspondence should be addressed to Ilker Ustabas; ilker.ustabas@erdogan.edu.tr
}

Received 6 August 2021; Revised 8 September 2021; Accepted 21 September 2021; Published 8 October 2021

Academic Editor: Abdulkadir Cuneyt Aydin

Copyright (c) 2021 Ilker Ustabas et al. This is an open access article distributed under the Creative Commons Attribution License, which permits unrestricted use, distribution, and reproduction in any medium, provided the original work is properly cited.

\begin{abstract}
Made up of an engineered mix of ordinary Portland cement (OPC) with artificial pozzolans such as trass, fly ash, and slag, the blended cements have been intensely employed within cementitious materials. The main reasons behind this intensive use can be clarified by enhanced workability/strength, the high resistance to chloride/sulfate, reduced permeability/alkali-silica reaction, and a drop in the heat generated by cement's hydration. The use of cementitious blends within concrete not only offers durable products but also cuts climate impact by energy saving and falling $\mathrm{CO}_{2}$ emissions. This study presents pozzolanic effect on the hydration heat of cements incorporating fly ash, obsidian, and slag additives. The blended cements were manufactured by three different replacement ratios of $20 \%, 30 \%$, and $50 \%$. The change in the hydration heat of obsidian-, fly ash-, and slag-based cements was observed by several Turkish standards (TS EN 196-8 and TS EN 196-9). Mortars were used for determining the uniaxial strengths of obsidian-, fly ash-, and slag-based cements. The results show that cement's hydration heat decreases as the rate of additives (e.g., obsidian) increases from $20 \%$ to $50 \%$. The cement's fineness greatly affects its hydration heat. Increasing the refinement of pozzolanic material to a certain level (30\%) leads to an increase in the hydration temperature. After reaching this level, there is no clear relation between the fineness and the replacement rate of pozzolans. As a result, the findings of this work will provide a good understanding of artificial pozzolans on performance and quality of obsidian-, fly ash-, and slag-based cements.
\end{abstract}

\section{Introduction}

The cement's hydration is a reaction which exothermically causes a heat output. This resulting heat can damage concrete or large-sized reinforced concrete elements by triggering it to crack if it exceeds certain values in fresh concrete or the temperature difference between two points surpassing certain values. To prevent such damage, some limitations have been introduced in the relevant standards for the quantity of the temperature released in the concrete and cement's hydration heat [1]. According to the TS 13515 standard, the highest temperature in fresh concrete or concrete structural elements with dimensions exceeding $90 \mathrm{~cm}$ thickness should not exceed $65^{\circ} \mathrm{C}$. The variance between internal and outside temperature of concrete should not exceed $25^{\circ} \mathrm{C}$ and $20^{\circ} \mathrm{C}$ for the concretes with and without reinforcement, respectively [1]. It is recommended to use cements with low-hydration heat in concrete which eliminate or pointedly diminish the risk of being damaged by the hydration heat. As the hydration heat of general-use cements is governed by the rules stated in EN 196-8 (7-day) or EN 196-9 (41-hour) standard, it should not be more than $270 \mathrm{~J} / \mathrm{g}$. Therefore, the hydration heat should not exceed $300 \mathrm{~J} / \mathrm{g}$ in low-hydration-temperature cements [2]. The use of pozzolans is the most commonly used method in the production of low-hydration cement [3]. Pozzolanic additives affect greatly the hydration reactions of cement [4]. Resulting in a decrease in the ratio of clinker and gypsum because of pozzolans added in the blended cements, less heat output occurs in concrete in comparison with ordinary Portland cement. In addition, the encircling of the pozzolan parts around the clinker grains in the cement causes a slowdown 
in cement's hydration rate and delays heat output $[5,6]$. Pozzolans are widely used in cement making due to decreasing the cement's hydration heat and providing the benefit to concrete properties [7].

The content and fineness of the pozzolans used in the cement affect the speed of cement hydration, the strength gain of the cement, setting start, setting finish, and standard consistency values [8]. Fly ash, among other additives, has a fine structure as it is obtained by filtering the fumes into a thermal power plant chimney and can be used in the cement without being subjected to grinding. However, additives such as clinker, slag, and pozzolans must be ground to certain fineness values by using grinders. The limit values for the cement fineness are generally given according to the amount of material passing through $32-\mu \mathrm{m}, 45-\mu \mathrm{m}, 90-\mu \mathrm{m}$, and $200-\mu \mathrm{m}$ sieves or the Blaine fineness. According to the TS 25 standard, the specific surface value of the natural pozzolan to be used in the cement should be at least $4000 \mathrm{~cm}^{2} / \mathrm{g} \pm 25 \%$ [9]. For the refinement of the limestone to be used in the cement, its specific surface should be ground to nearly $5000 \mathrm{~cm}^{2} / \mathrm{g}$. Pozzolan fineness also affects the early and late strength of cement. Saedi et al. [10] detected an increase in the strength values of up to twice in mortars with alkali activation and two different Blaine's fineness values, $2900 \mathrm{~cm}^{2} / \mathrm{g}$ and $4200 \mathrm{~cm}^{2} / \mathrm{g}$ [10]. Khan and Amin [11] indicated that ultrathin volcanic ash- and slag-based mortars raise the strength acquisition of mortars with normal fineness. Khan and Alhozaimy [12] stated that the cements with natural pozzolans ground to 1800,3400 , and $375 \mathrm{~cm}^{2} / \mathrm{g}$ Blaine fineness provide improvements regarding the stability performance. Moghaddam et al. [13] stated that for a given cement, fine fly ashes offer more hydration temperature than coarse ones. Pozzolans are substances causing a drop in cement's hydration rate, a rise in setting start time, and a slowdown in the strength-gaining speed. Otherwise, pozzolans that do not have suitable fineness will raise undesirable situations, such as decreasing the strength-gaining speed and delaying the setting start time in cement. Niu et al. [14] used blast furnace slag in cement by grinding it to ultrathinness so as not to extend the setting start time of the cement. They stated that ultrafine slag tended to decline in the setting start time of the cement and the standard consistency. The fineness of the pozzolan used in the cement with additives also affects the setting time of the cement [15]. In the cements with blast furnace slag and natural pozzolan, a $13.6 \%$ strength increase was observed as pozzolan fineness increased from $2800 \mathrm{~cm}^{2} / \mathrm{g}$ to $4200 \mathrm{~cm}^{2} / \mathrm{g}$. As the pozzolan ratio increases, the grain diameters of cement are collected in a narrow gap and the hydration of cement exhibits a decrease in the temperature [16]. Particles with small grains have a larger surface, and when they are exposed to water, they hydrate faster and cause the mortar to gain more mechanical strength. Cement with finer particles also releases more hydration heat [14]. A fast hydration reaction takes place in the cements with high thinness and alkali level values [7]. Baran and Pichniarczyk [17] stated that there is a clear link between concrete's strength and temperature of cement hydration and the cement with high strength has higher hydration heat. Han et al. [18] stated that fly ash slows down the hydration reaction at early stages, falling the temperature of cement hydration. Thongsanitgarn et al. [19] determined the hydration heat of fly ash- and limestonebased cements by isothermal calorimetry. They declared that a rise in limestone powder's fineness increases the hydration temperature of cement. Tydlitát et al. [20] examined zeolite's hydration heat by isothermal calorimetry and determined at what rate the zeolite addition to the cement reduced the hydration heat. As a result, one can say that the hydration heat of pozzolans is a hot topic [21]. Reducing the hydration temperature of cement is crucial, mainly in mass concretes and thick concrete structural elements [22].

Figure 1 shows the cement hydration mechanism which is basically divided into five phases $[23,24]$. In stage one, as cement is mixed with water, aluminate reacts with water and rapid heat is released. The reaction of sulfate with water surrounds the cement grains to form ettringite. In stage two, which is the dormant phase of the cement for 2-4 hours and the cement grains of ettringite gel, the cement grains are kept under pressure by wrapping them around. In stage three, after supersaturating $\mathrm{Ca}$-rich pore solution, alite and belite transform into $\mathrm{C}-\mathrm{S}-\mathrm{H}$ and $\mathrm{CH}$ gels without dissolving, and it begins to form with major heat evolution. At stage four, the contact of C-S-H and $\mathrm{CH}$ products with water and anhydrate particles retards the reaction of alite (i.e., the basic phase required for setting/increasing early strength gains), thus reducing the hydration heat of cement. Sulfate's quantity begins to decline, and aluminate responds with ettringite $\left(\mathrm{Ca}-\mathrm{Al}-\mathrm{SO}_{4}^{2-}\right)$ to construct monosulfate, which may lead to low temperature. Figure 1 shows three temperature peak values occurring after the hydration stages of cement [23].

Two main techniques are employed for appreciating the temperature of cement hydration: (i) the chemical technique and (ii) the semiadiabatic technique. TS EN 196-8 is a chemical technique in which cement's hydration heat is determined by calculating the temperature released by dissolving cement in acid in a calorimeter. When determining the hydration temperature according to TS EN 1968 , the heat flow diagram is a reverse arc curve that first rises and then descends, and it does not conform to the curve in Figure 1. In the ASTM C1679 standard method, with the help of isothermal calorimetry, the hydration heat of cement is evaluated by the temperature released by the reaction with the cement. In this way, it partly resembles the shape in Figure 1, regarding determination of hydration temperature. TS EN 196-9 is a semiadiabatic technique in which cement hydration temperature is determined by the temperature released from the mortar sample consisting of a cement, water, and sand mixture. Since the mortar mixture is prepared outside and placed inside the calorimeter, the sudden temperature rises in Stage I cannot be detected clearly in this method.

This work inspects the hydration temperatures of fly ash, slag- and obsidian-based cements, using the TS EN 196-8 and TS EN 196-9 methods. How obsidian affects the hydration heat of cement, in comparison with cement containing fly ash and slag additives, was measured. How pozzolan fineness affects the hydration heat of cement was 


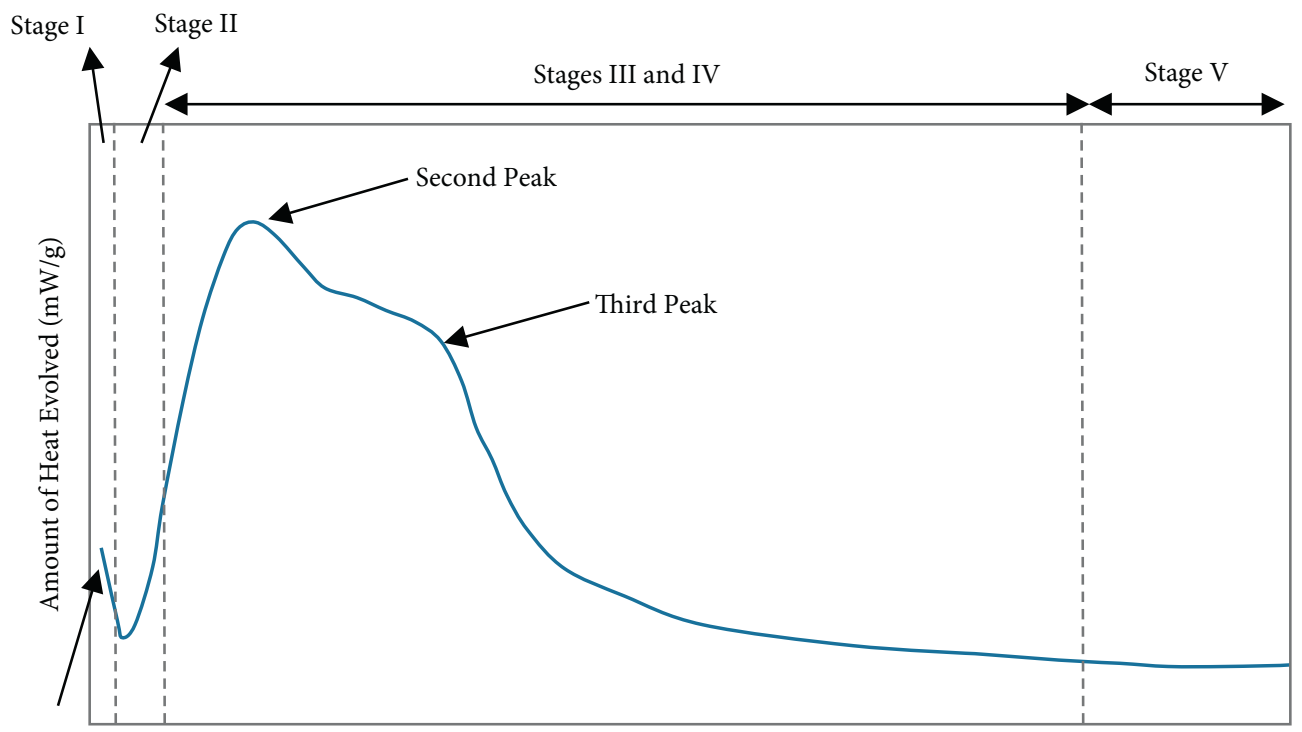

First Peak

Time (h)

Figure 1: Schematic view of the hydration stages of cement (modified after [23]).

investigated. Although the hydration temperatures related to cement incorporating fly ash and slag additives exist in the literature, there is no work being conducted on the hydration heat values of obsidian (a.k.a., volcanic glass), which provides the originality of the present work. Additionally, in the hydration heat measurements made according to TS EN 196-8 and TS EN 196-9, this study indicates clearly that the temperature difference value of cements incorporating fly ash, obsidian, and slag additives decreases as the mineral additive ratio increases. Additionally, mineral additives are found to decrease the hydration heat of cement.

\section{Materials and Methods}

2.1. Materials. The cement used in this study is typically produced by adding $20 \%, 30 \%$, and $50 \%$ fly ash, slag, and ground obsidian to CEM I 42.5R. Three different fineness levels of fly ash, slag, and obsidian additives were added to CEM I 42.5R. Table 1 lists the different fineness levels of 10 different cement types. Table 2 lists cement's chemical composition and the reactive silica contents of pozzolans.

The fly ash utilized during the experiments was sampled from the Tuncbilek thermal power plant in the province of Kutahya (Turkey), while the slag additive was sampled from the Karabuk iron and steel plant. Obsidian, also known as volcanic glass, is a rare substance used as a pozzolan in cement in the literature. In the region in which this study was carried out, there is lots of obsidian in the area of $10 \mathrm{~km}^{2}$ (Figure 2).

Figure 3 shows obsidian located in the Rize-Ikizdere locality which is in sharp glass form. Obsidian having a thick and massive appearance is spread over a wide area, reaching up to six meters thick. The obsidian structure is sharp and like broken glass, which is dangerous for humans/animals to wander in this area. The obsidian used as a pozzolan in this study was pulverized and added to cement [8].
2.2. The Fineness of the Cements Used. The fly ash and slag additives were ground to different fineness levels in a ball mill. Obsidian was crushed by using a jaw crusher at laboratory first and then ground by using a ball mill. Table 1 lists the cement fineness. Obsidian was ground in 45,60 , and 75 minutes and fly ash and slag in 20 and 40 minutes to obtain the targeted pozzolan fineness levels within the scope of the study.

2.3. Determination of Hydration Heat of Cement. The solution and semiadiabatic methods are used to study the hydration heat of cement. The hydration heat of additive-based cements (e.g., obsidian, fly ash, and slag) with three fineness levels and cement without pozzolan was measured by using two different Turkish standard methods (i.e., TS EN 198-8 and TS EN 196-9).

The determination of the hydration heat of cement, based on TS EN 196-8 standard procedure, is calculated by dissolving the cement and hydrated cement in the solution made by adding $2.76 \mathrm{~g}$ of $40 \%$ hydrofluoric acid solution to each $100 \mathrm{~g}$ of nitric acid solution of $2 \pm 0.01 \mathrm{~mol} / \mathrm{liter}$. The mass ratio of total acid/dry cement mixtures is $140 \pm 2 \mathrm{~g}$ of the dry cement dissolved in the acid solution. The solution's temperature escalation is measured with a thermometer with $0.002^{\circ} \mathrm{C}$ precision.

After 7-day hardened cement prepared by adding $100 \mathrm{~g}$ of cement to $40 \mathrm{~g}$ of water is crushed and sieved, the temperature released by its dissolution in acid in hydrated cement, which is $40 \%$ more than the mass of dry cement, is measured. The hydration heat of the cement is calculated using the following equation from the temperature differences obtained:

$$
\mathrm{H}_{i}=\mathrm{Q}_{a}-\mathrm{Q}_{i},
$$

where $Q_{a}$ shows the melting temperature of dry cement in solution. $Q_{a}$ is calculated by the following equation: 
TABLE 1: Fineness values of cements containing different pozzolanic additives.

\begin{tabular}{lcccc}
\hline Cements with different additives & \multicolumn{2}{c}{ Percentage left on sieve } & Blaine fineness $\left(\mathrm{cm}^{2} / \mathrm{g}\right)$ \\
\hline Obsidian (OBS) 45 & $200 \mu \mathrm{m}$ & $90 \mu \mathrm{m}$ & $45 \mu \mathrm{m}$ & 4752 \\
OBS 60 & 0 & 5.3 & 40.2 & 5502 \\
OBS 75 & 0 & 2.5 & 28.5 & 6135 \\
Fly ash (FA) & 0 & 0 & 1.7 & 4.7 \\
FA 20 & 0 & 0 & 7.5 & 5263 \\
FA 40 & 0 & 0 & 6.8 & 6705 \\
Blast furnace slag (BFS) & 0 & 0 & 9.8 & 4713 \\
BFS 20 & 0 & 0 & 6.9 & 5623 \\
BFS 40 & 0 & 0 & 19.5 & 6125 \\
CEM I 42.5R & 0 & 0 & 4424 \\
\hline
\end{tabular}

TABLe 2: A summary of oxide analysis of additives utilized in the experiments (\%).

\begin{tabular}{lcccc}
\hline Oxides & CEM I 42.5R & Obsidian & Fly ash & Blast furnace slag \\
\hline $\mathrm{CaO}$ & 63.52 & 0.75 & 3.85 & 31.23 \\
$\mathrm{SiO}_{2}$ & 18.48 & 71.56 & 51.65 & 17.65 \\
$\mathrm{Al}_{2} \mathrm{O}_{3}$ & 5.25 & 12.52 & 11.51 & 10.52 \\
$\mathrm{Fe}_{2} \mathrm{O}_{3}$ & 3.48 & 1.53 & 4.62 & 0.63 \\
$\mathrm{MgO}$ & 1.01 & 0.17 & 2.05 & 8.06 \\
$\mathrm{~K}_{2} \mathrm{O}$ & 1.13 & 5.21 & 0.65 & 1.53 \\
$\mathrm{Na}_{2} \mathrm{O}$ & 0.36 & 3.95 & 0.112 & 0.35 \\
$\mathrm{P}_{2} \mathrm{O}_{5}$ & 0.071 & 0.011 & 1.25 & 0.002 \\
$\mathrm{SO}_{3}$ & 2.775 & 0.003 & 0.68 & 3.57 \\
$\mathrm{TiO}_{2}$ & 0.13 & 0.17 & 0.013 & 0.41 \\
$\mathrm{Sr}$ & 0.075 & 0.012 & 0.11 & 0.061 \\
$\mathrm{Cr}_{2} \mathrm{O}_{3}$ & 0.06 & 0.065 & 0.12 & 0.13 \\
$\mathrm{MnO}$ & 0.25 & 0.05 & 2.13 & 1.25 \\
Loss on ignition & 2.76 & 2.02 & 47.13 & 4.12 \\
$\mathrm{Reactive} \mathrm{silica}$ & - & 39.34 & & 43.01 \\
\hline
\end{tabular}

$$
Q_{a}=\left(\frac{C \cdot \Delta T_{c}}{P}\right)+0.8\left(T_{f}-T_{a}\right)+0.8\left(T_{f}-20\right)\left(\frac{J}{g}\right)
$$

$\Delta T_{c}$ is the modified temperature increase, Kelvin $(\mathrm{K})$ is the calorimeter's thermal capacity $(\mathrm{J} / \mathrm{K}), P$ is the dry cement's amount $(\mathrm{g}), T_{f}$ is the dry cement's temperature at the end of the dissolution period $\left({ }^{\circ} \mathrm{C}\right)$, and $T_{a}$ is the environment in which the dry cement was added to the calorimeter. The temperature $\left({ }^{\circ} \mathrm{C}\right), 0.8$, is the dry cement's heat $(\mathrm{J} / \mathrm{g} \mathrm{K})$, and -0.8 is the temperature coefficient of the melting heat of dry cement $(\mathrm{J} / \mathrm{g} \mathrm{K})$.

$$
\begin{aligned}
& \Delta T_{c} \text { for all cements: } \Delta T_{c}=\left(T_{30}-T_{0}\right)-2\left(\left(T_{0}-T_{-15}\right)\right. \\
& \left.-K\left(T_{30}-T_{0}\right)\right) \text {, }
\end{aligned}
$$

$\Delta T_{c}$ for all cements: $\Delta T_{c}=\left(T_{30}-T_{0}\right)-2\left(T_{45}-T_{30}\right)$.

$\Delta T_{c}$ is calculated from the above equations. The numbers shown as indices under $T$ in the above equations show the temperatures taken from thermometer at a specific time. $Q_{i}$ indicates the melting temperature of the hydrated cement in the solution. $Q_{i}$ is determined by the following equation:

$$
Q_{i}=\left(\frac{C \cdot \Delta T_{c}}{P \cdot F}\right)+1.7\left(T_{f}-T_{a}\right)+1.3\left(T_{f}-20\right)\left(\frac{J}{g}\right),
$$

where $P$ is the hydrated cement's amount $(\mathrm{g}), T_{f}$ is the hydrated cement's temperature at the end of the dissolution age $\left({ }^{\circ} \mathrm{C}\right), T_{a}$ is the ambient temperature $\left({ }^{\circ} \mathrm{C}\right)$ when the hydrate cement is added to the calorimeter, $F$ is the modified bound water factor, 1.7 is the hydrated cement's specific heat $\left(\mathrm{J} / \mathrm{gK}^{-1}\right)$, and -1.3 is the temperature coefficient of the melting heat of the hydrated cement $\left(\mathrm{J}_{\mathrm{gK}}^{-1}\right)$. The correction factor $(F)$ for bound water is calculated by the following equation:

$$
F=\frac{\left(100-m_{h}\right)}{\left(100-m_{a}\right)}
$$

where $m_{h}$ indicates the mass change (\%) of the hydrated sample afterglow and $m_{a}$ is the mass change (\%) of the dry sample afterglow.

The hydration temperatures of cements incorporating additives such as obsidian, fly ash, and slag were measured according to TS EN $196-8$ by using the calorimeter (Figure 4).

TS EN 196-9 is another technique in which the hydration heat of cement is calculated by using the semiadiabatic technique. The test sample is manufactured by blending 


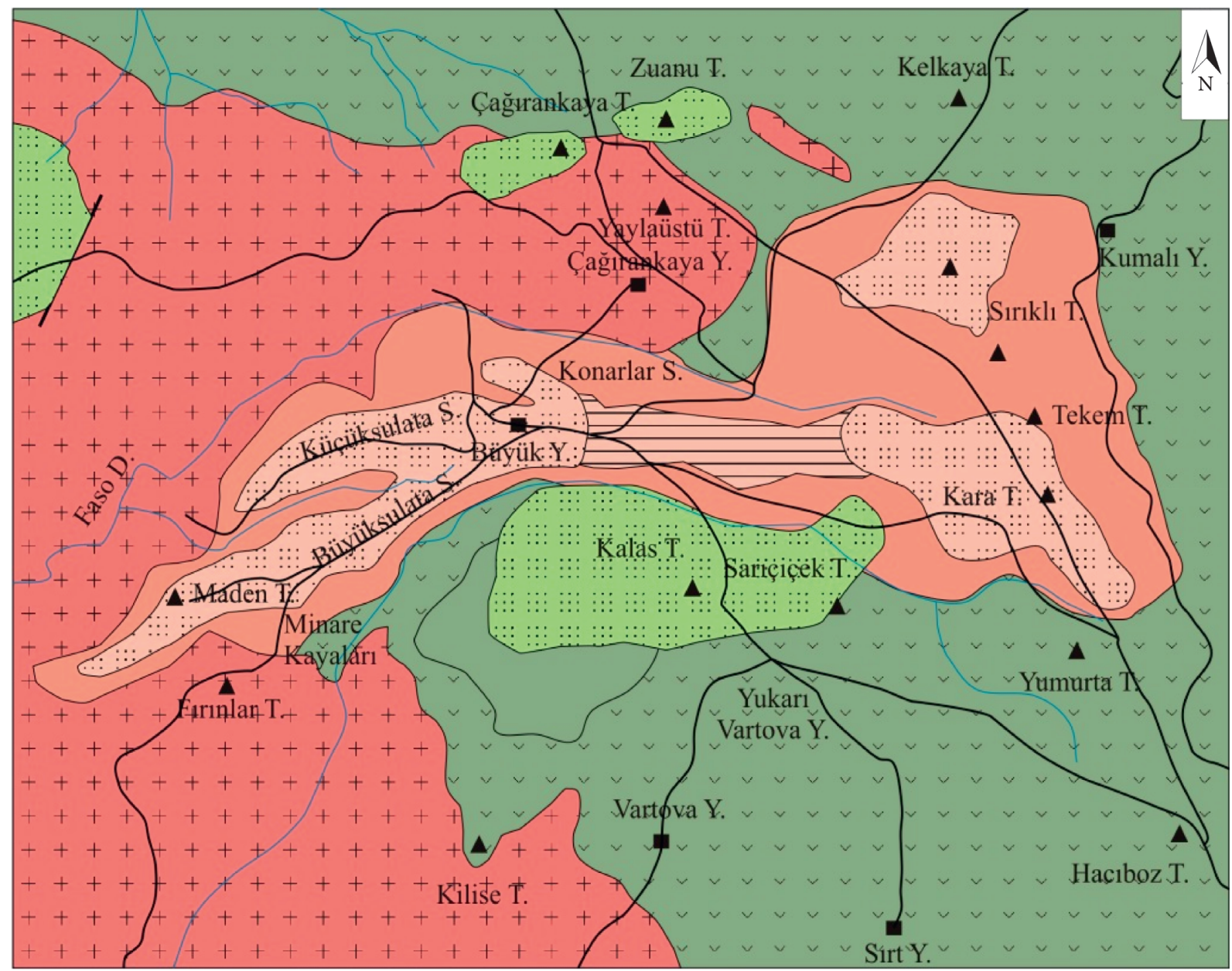

Obsidian

Ehyolite-Obsidian

Rhyolite

Trachyandesite

Basanite

Ikizdere granodiorite

Basaltic andesite
$\neg$ Unit limit
$\triangle$ Fault line
$\sim$ Stabilized road
$\leadsto$ Stream
$\triangle$ Hill
- Residential area

Figure 2: The geological map of Rize Buyukyayla obsidians and their immediate surroundings.

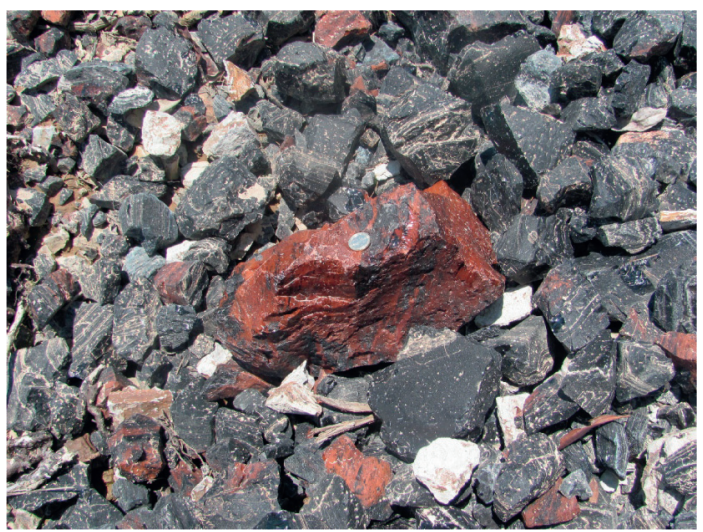

Figure 3: Photo of the obsidian accumulated in rash form. 


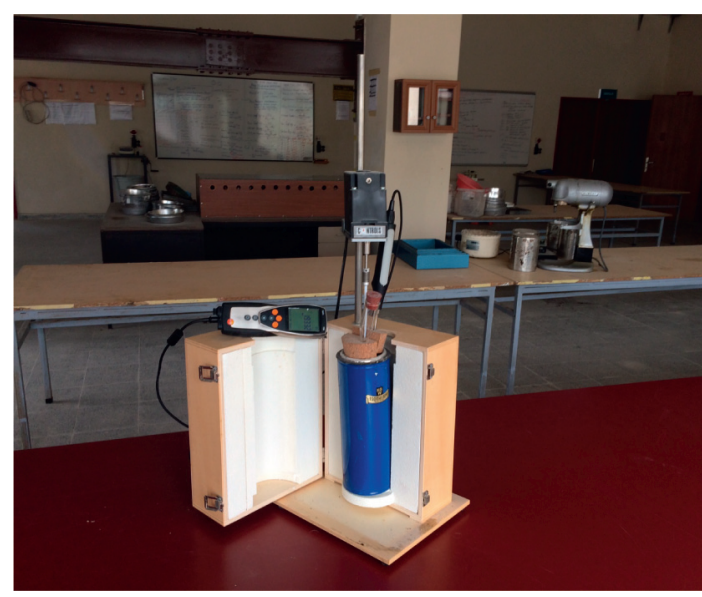

Figure 4: Photo of the calorimeter used by the chemical technique.

$360 \mathrm{~g}$ of cement and $180 \mathrm{~g}$ of water and sand, as given clearly in TS EN 196-9 standard. The total material amount is $1575 \mathrm{~g}$, and hydration heat of cement is measured on two main specimens by using a calorimeter: one is the reference while the other is the measurement of specimen. At temperature readings, the temperature rise of sample $\left(\theta_{t}\right)$ is mainly calculated from the temperature differences between $T_{s}$ and $T_{r}$ specimens through the calorimeter. The hydration heat $(\square)$ of cement is determined by the following equation:where $m_{c}$ is the cement's quantity $(\mathrm{g}), t$ is the interval of cement hydration (h), $c$ is the thermal capacity of calorimeter $\left(\mathrm{J} . \mathrm{K}^{-1}\right)$, and $\alpha$ is the coefficient of temperature losses of the calorimeter $\left(\mathrm{J} \cdot \mathrm{h}^{-1} \cdot \mathrm{K}^{-1}\right)$.

$$
Q=\frac{c}{m_{c}} \theta_{t}+\frac{1}{m_{c}} \sum_{i=1}^{i=1} \overline{\alpha_{i}} \cdot \overline{\theta_{i}} \cdot \Delta t_{i}
$$

Figure 5 shows the hydration heat measurement of cements incorporating additives such as obsidians, fly ashes, and slags, as given clearly by TS EN 196-9 standard. The measurement of hydration temperature in the desired time was performed at laboratory, and it found to be $20^{\circ} \mathrm{C}$ by using a device.

\section{Results and Discussion}

3.1. Influence of Grinding Time on Temperature Difference of Obsidian-Incorporated Cements. Figure 6 shows the temperature differences measured by subtracting the temperatures measured in CEM I 42.5R and in cement prepared by adding $20 \%, 30 \%$, and $50 \%$ obsidian ground for $45 \mathrm{~min}$ from the temperatures measured in the reference mortars. The highest temperature difference of $21.6^{\circ} \mathrm{C}$ was found in the 26th hour of CEM I 42.5R cement without pozzolan. Erdogan and Kocak [21] calculated the heat flow and hydration heat in 27 types of cement according to the ASTM C1679 standard. Since less cement is used in the ASTM C1679 standard in comparison with the TS EN 196-9 standard, the highest heat flow in ordinary Portland cement reaches nearly 9 hours, and the heat flow decreases to the test starting temperature at 42 hours [21]. The technique used

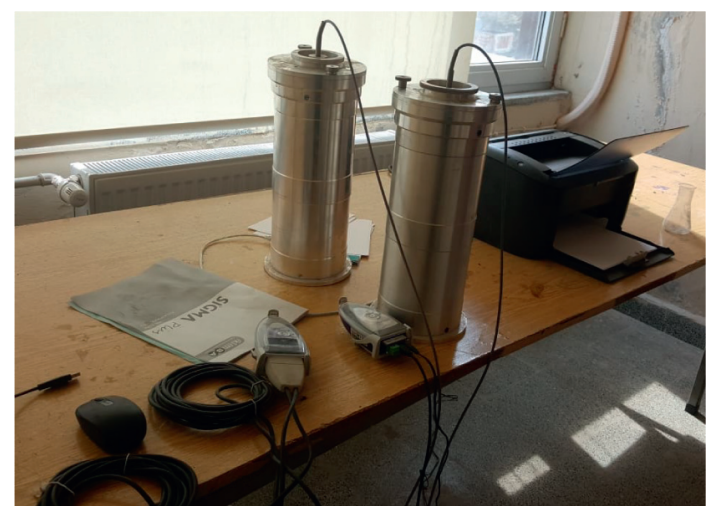

FIgURE 5: The measurement of computer-controlled hydration temperature in the blended cement.

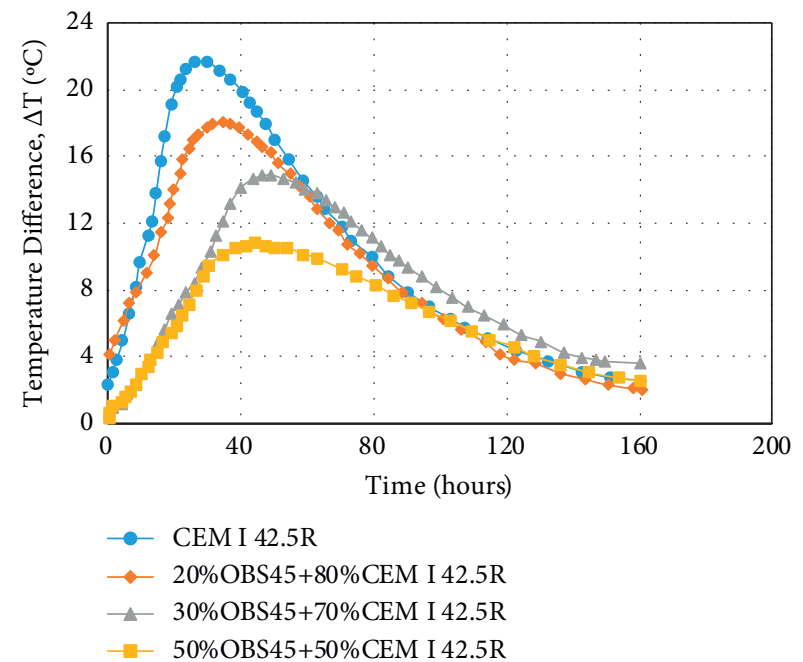

FIgURE 6: Temperature difference of CEM I 42.5R and 45-min ground $20 \%, 30 \%$, and $50 \%$ obsidian-added cements.

affects greatly the highest heat flow and heat flow exit time of the cement.

Figure 6 also shows that, in 20\% obsidian-added cement ground for $45 \mathrm{~min}$, the highest temperature is $18.03^{\circ} \mathrm{C}$ at the 34 th hour; in the $30 \%$ obsidian-added cement ground for $45 \mathrm{~min}$, it is $14.88^{\circ} \mathrm{C}$ at the 49 th hour; and in the $50 \%$ obsidian-added cement ground for $45 \mathrm{~min}$, it is $10.82^{\circ} \mathrm{C}$ at the 44th hour. The highest temperature difference was found. This means that increasing the rate of obsidian added to cement reduces the maximum temperature differences of cement and extends the time required to reach the highest temperature difference. This shows that the pozzolan surrounds the cement grains, causing the heat output to be slower. Han et al. [18] and Erdogan and Kocak [21] measured the heat flow and hydration temperatures in the cement in which $3.5 \mathrm{~g}$ of cement was blended with $1.4 \mathrm{~g}$ of water, based on the ASTM C1679 standard. They encountered three temperature increase peaks when the heat flow reached the highest value between 6 and 10 hours. Since the amount of cement used in the TS EN 196-9 method in this study is more than that used in the ASTM C1679 standard and a blend of sand and mortar is made and placed in the 
container, the temperature during the initial mixing of water and cement cannot be measured. In the ASTM C1679 method, a temperature peak value is seen in the TS EN 196-9 method, just like the second temperature peak value. The heat leaving the cement reaches its peak value in a longer time and at a higher amount. Adding obsidian ground for $45 \mathrm{~min}$ to CEM I $42.5 \mathrm{R}$ reduces the resulting temperature and extends the time to reach the highest value.

Figure 7 shows that, as the obsidian addition rate increases in $20 \%, 30 \%$, and $50 \%$ obsidian-added cements ground for $60 \mathrm{~min}$, the time to reach the highest temperature difference of the obsidian cement compared to Portland cement increases and the temperature difference drops. The highest temperature difference is $18.7286^{\circ} \mathrm{C}$ at 28 hours in cements with $20 \%$ obsidian added, ground for $60 \mathrm{~min}$; $16.6996^{\circ} \mathrm{C}$ at 28 hours in $30 \%$ obsidian-added cement, the highest temperature difference per hour; and $15.7689^{\circ} \mathrm{C}$ at 36 hours for $50 \%$ obsidian-added cements. The highest temperature difference is $12.8704^{\circ} \mathrm{C}$ per hour for milling for $60 \mathrm{~min}$; obsidian-added cement with Blaine fineness of $5497 \mathrm{~cm}^{2} / \mathrm{g}$ was ground for $45 \mathrm{~min}$ and reached the highest temperature difference in a shorter time compared to cement with a Blaine fineness of $4746 \mathrm{~cm}^{2} / \mathrm{g}$. Increasing the milling time from 45 to $60 \mathrm{~min}$ led to a temperature difference by $3.8 \%$ in $20 \%$ obsidian-added cement, $12.2 \%$ in $30 \%$ obsidian-added cement, and $19 \%$ in $50 \%$ obsidianadded cement. Addition of finer obsidian to the cement reduced the time during which the highest temperature difference occurred and increased the temperature difference.

Figure 8 shows the temperature differences of $20 \%, 30 \%$, and $50 \%$ obsidian-added cements ground for $75 \mathrm{~min}$ and cement without additives. The temperature differences in obsidian-added cement ground for $75 \mathrm{~min}$ are $19.2034^{\circ} \mathrm{C}$ at 27 hours in the $20 \%$ obsidian-added cement, $17.8642^{\circ} \mathrm{C}$ at 28 hours in the $30 \%$ obsidian-added cement, and $12.8515^{\circ} \mathrm{C}$ at 32 hours in the $50 \%$ obsidian-added cement. There was a decrease/increase in temperature difference in obsidianadded cement whose Blaine fineness increased to $6122 \mathrm{~cm}^{2} / \mathrm{g}$ by grinding for $75 \mathrm{~min}$, when the peak temperature difference was observed compared to 45- and 60-min ground obsidianadded cements. In obsidian-added cements, as the amount of obsidian increased, the temperature difference value decreased; as the fineness of the obsidian decreased, the temperature difference peak and the temperature difference value increased. This is due to the increase in the speed of the pozzolan entering into reactions as a result of the increase in the fineness of the pozzolan. The issues identified in this study were determined by Binici et al. [16] and Ardoga et al. [4]. Accordingly, as the amount of pozzolan increased, the hydration heat of cement decreased, and when the fineness of cement increased, the reaction rates were determined.

3.2. Effect of Grinding Time on Hydration Heat of ObsidianIncorporated Cements. Figure 9 shows the hydration temperatures of $20 \%, 30 \%$, and $50 \%$ obsidian-added cements ground for $45 \mathrm{~min}$ and the temperature differences until the 160th hour. The cement hydration heat at the 41 st hour was

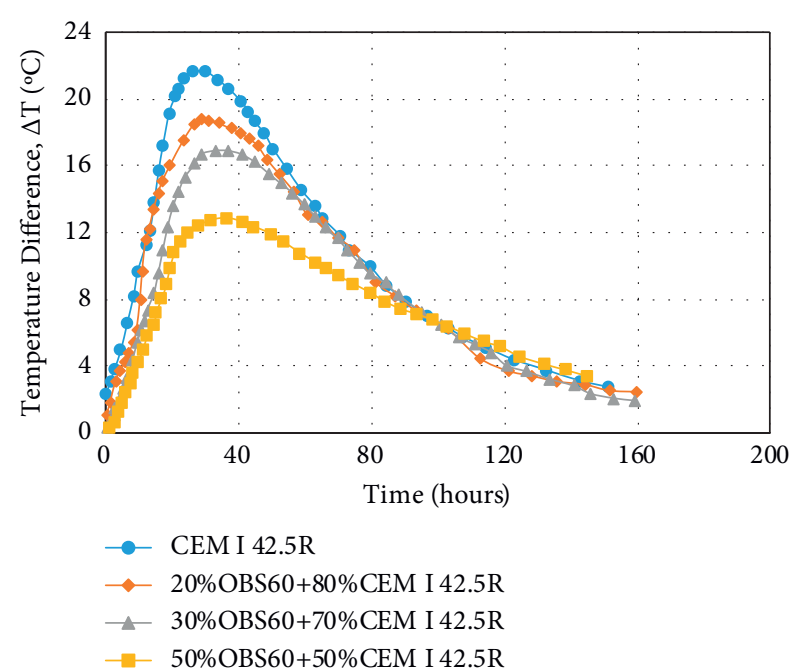

Figure 7: Temperature difference of CEM I 42.5R and 60-min ground $20 \%, 30 \%$, and $50 \%$ obsidian-added cements.

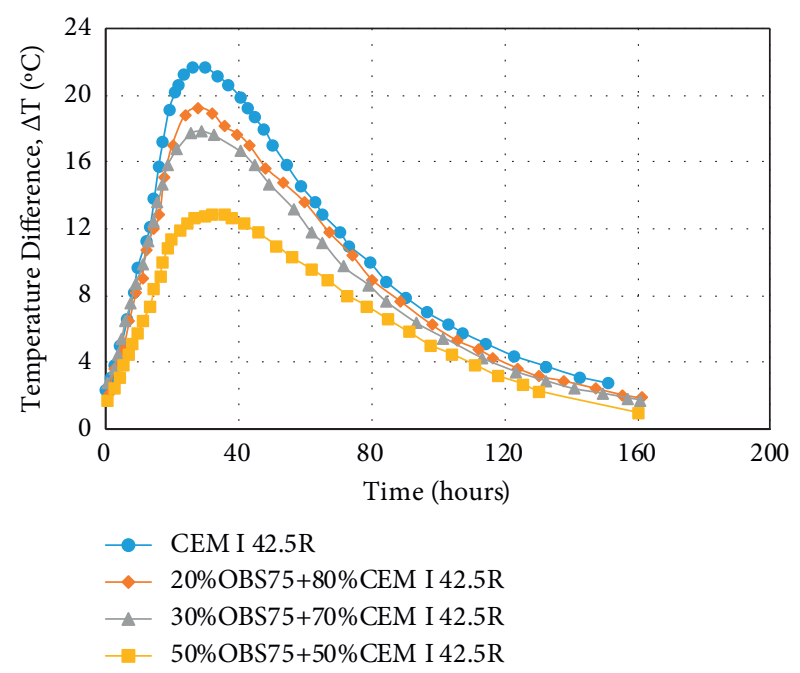

Figure 8: Temperature difference of CEM I 42.5R and 75-min ground $20 \%, 30 \%$, and $50 \%$ obsidian-added cements.

$267.2 \mathrm{~J} / \mathrm{g}$, and the hydration heat at the 160th hour was $362.9 \mathrm{~J} / \mathrm{g}$. The hydration temperature at the 41 st hour was $130.2 \mathrm{~J} / \mathrm{g}$ in the $20 \%$ obsidian-added cement milled for $45 \mathrm{~min}$. The hydration heat at the 160th hour was $326.9 \mathrm{~J} / \mathrm{g}$; the hydration temperature at the 41 st hour in the $30 \%$ obsidian-added cement was $149 \mathrm{~J} / \mathrm{g}$.

The hydration heat at the 160 th hour was $278.9 \mathrm{~J} / \mathrm{g}$, the hydration heat at the $41 \mathrm{st}$ hour was $120 \mathrm{~J} / \mathrm{g}$, and the heat at the 160th hour was $233.7 \mathrm{~J} / \mathrm{g}$ in the $50 \%$ obsidianadded cement ground for $45 \mathrm{~min}$. Based on the measurement according to TS EN 196-9, as the rate of obsidian added to cement increased, hydration temperatures decreased.

Figure 10 shows the hydration temperatures of $20 \%$, $30 \%$, and $50 \%$ obsidian-added cements ground for $60 \mathrm{~min}$ and the cements without additives, measured according to the TS EN 196-9 standard. The addition of obsidian reduced 


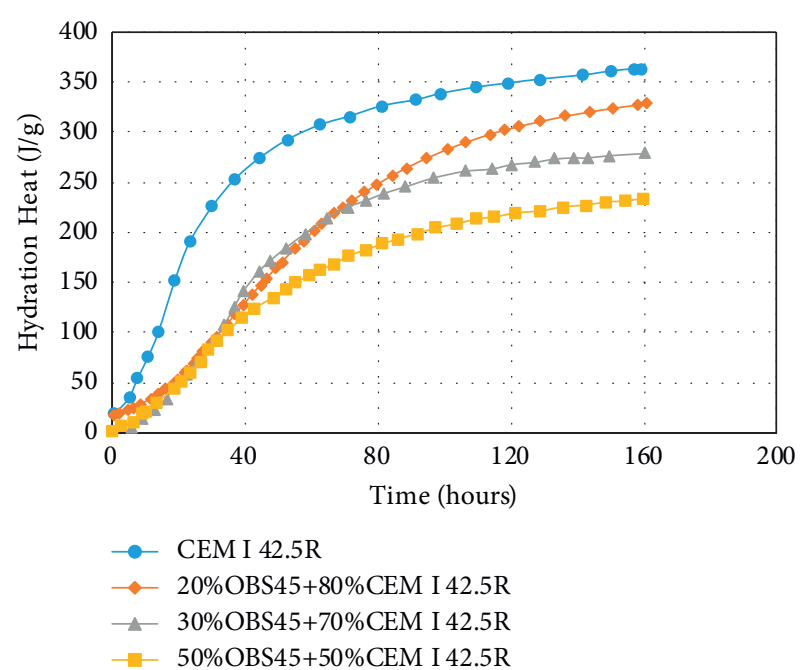

Figure 9: Measured hydration temperatures in CEM I 42.5R and 45 -min ground $20 \%, 30 \%$, and $50 \%$ obsidian-added cements.

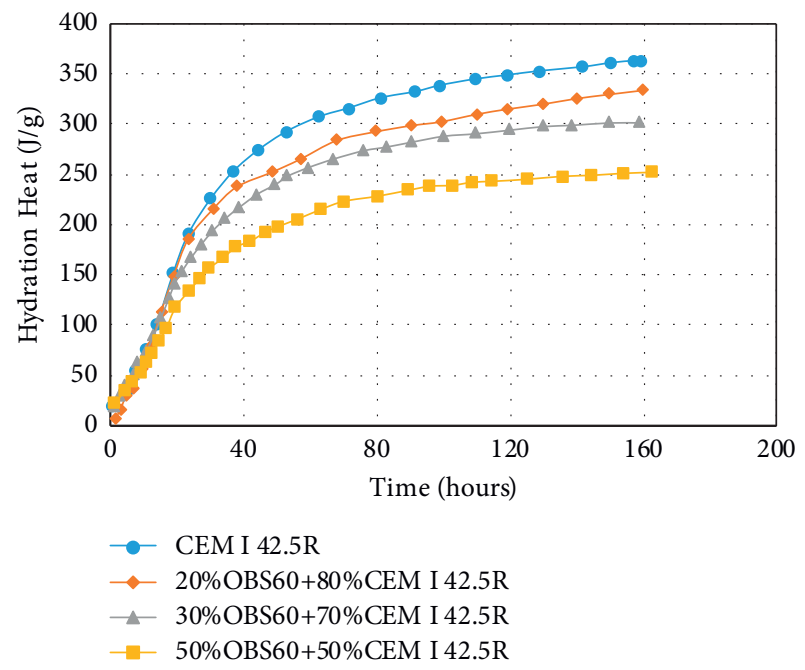

FIGURE 10: Measured hydration temperatures in CEM I 42.5R and 60 -min ground $20 \%, 30 \%$, and $50 \%$ obsidian-added cements.

the hydration heat of cement. As the fineness of the pozzolan added to the cement increased, the hydration heat of the obsidian-based cement increased when compared with the cement containing less obsidian added.

Figure 11 shows the hydration heat measured in $20 \%$, $30 \%$, and $50 \%$ obsidian-added cements ground for $75 \mathrm{~min}$. As the obsidian rate increased, the hydration heat of cement decreased. Thongsanitgarn et al. [19] indicated that the hydration heat augmented with growing fineness. The findings of this study were consistent with those of Thongsanitgarn et al. [19]. Since the cement has a heterogeneous composition, some hydration temperatures behave differently from this rule. In general, the rise in the amount of obsidian additives caused a drop in the hydration heat, and an increase in obsidian fineness caused a rise in the hydration heat in a short time.

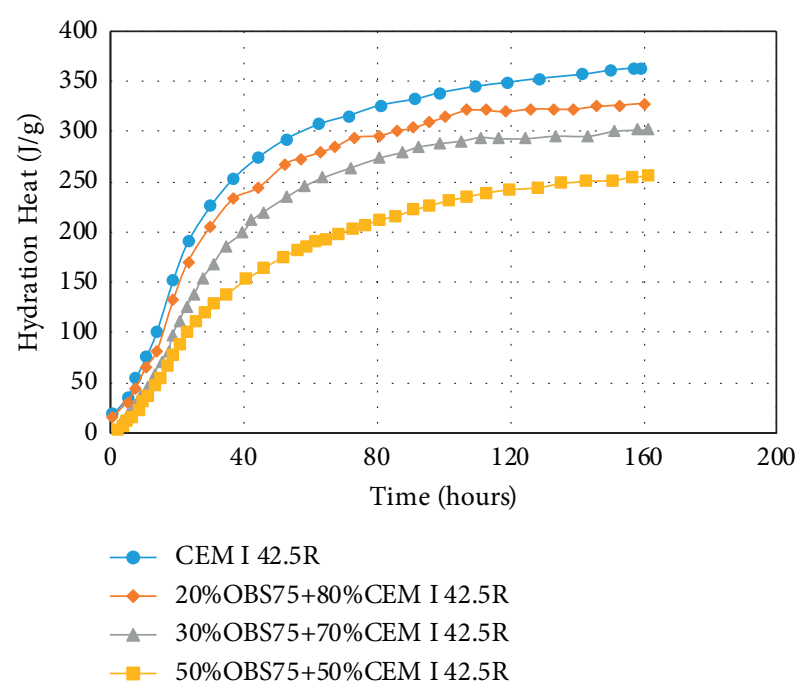

FIGURE 11: Measured hydration temperatures in CEM I 42.5R and 75 -min ground $20 \%, 30 \%$, and $50 \%$ obsidian-added cements.

3.3. Effect of Grinding Time on Hydration Heat of Slag-Incorporated Cements. Figure 12 shows the hydration temperatures calculated at the 41st and 160th hours in accordance with TS EN 196-9 for the unadulterated cement and blast furnace slag-added cements.

Figures 9-11 state that the hydration temperature decreased as the pozzolan ratio increased, and a rise in the hydration heat as the fineness augmented was not seen in the blast furnace slag-added cements. Although the hydration temperature decreased as the pozzolan additive ratio increased in the slag-added cements, no major change was detected in the hydration heat when the fineness of cements increased. This shows that when the pozzolan fineness reaches to a certain value, the increase in the fineness of the pozzolan does not increase significantly the hydration temperature.

3.4. Influence of Milling Time on Hydration Heat of Fly AshIncorporated Cements. Figure 13 shows the hydration temperatures calculated at the 41st and 160th hours according to TS EN 196-9 for OPC and OPC with fly ash additive. The fly ash added to the cement reduces hydration temperature of cement. Augmenting the fly ash's fineness did not cause a major rise in the hydration temperatures at the 41st and 160th hours. According to Han et al. [18], the cement hydration heat was $200 \mathrm{~J} / \mathrm{g}$ at the 41 st hour when $30 \%$ high blast furnace slag was added to the cement. On the other hand, the hydration heat was $175 \mathrm{~J} / \mathrm{g}$ when slag was added and $125 \mathrm{~J} / \mathrm{g}$ for $35 \%$ cement. It was measured as $150 \mathrm{~J} /$ $\mathrm{g}$ when fly ash was added and $85 \mathrm{~J} / \mathrm{g}$ when $65 \%$ fly ash was added [18]. The hydration temperatures of the cement replaced with blast furnace slag and fly ash additives, as investigated by Han et al. [18], were similar to those in this study. Demir et al. [25] showed experimentally that the fineness of pozzolanic material greatly affects hydration temperature when measured according to TS EN 196-9. 


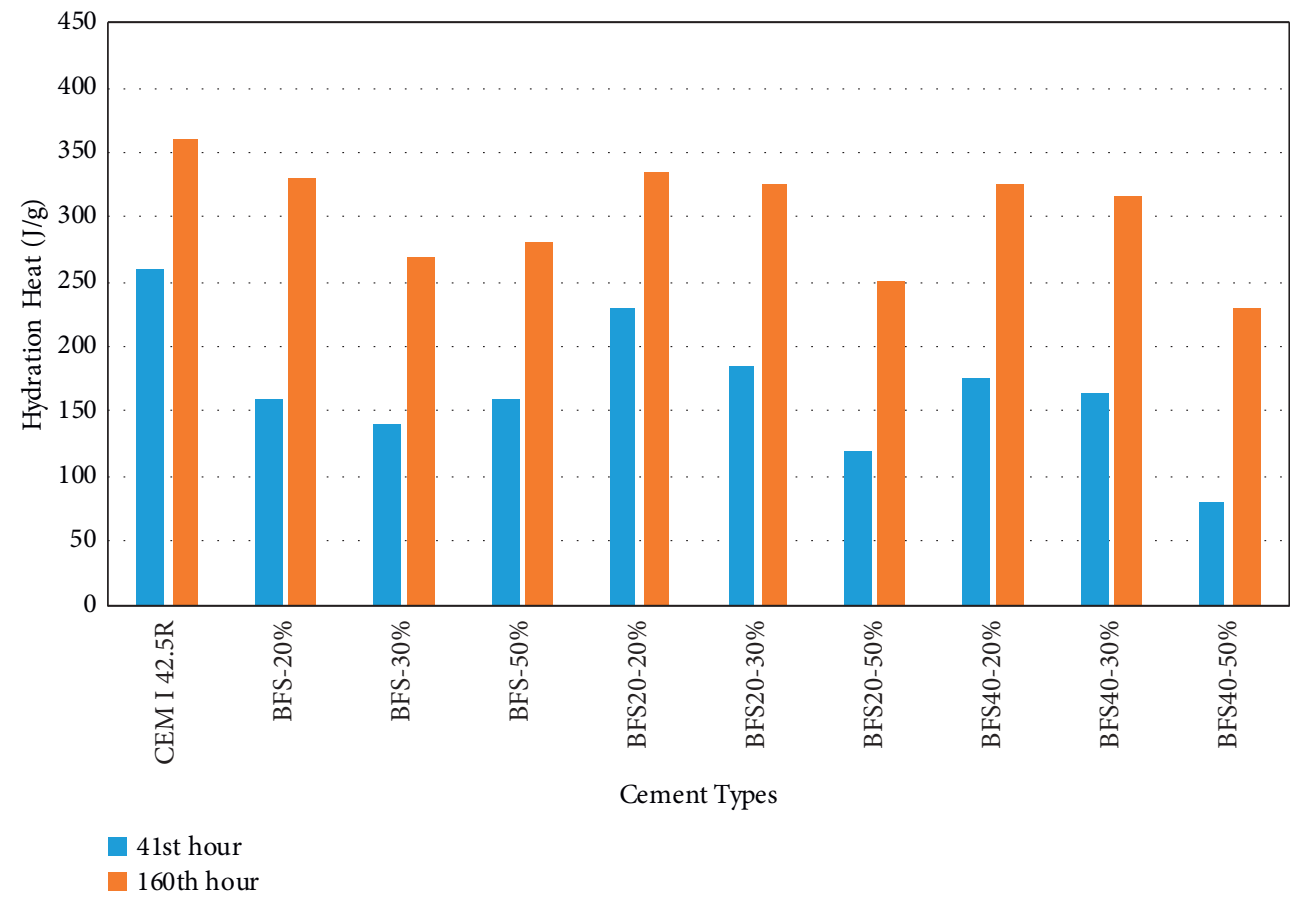

FiguRE 12: Hydration temperatures at 41st and 160th hours in CEM I 42.5R and 20\%, 30\%, and 50\% slag-added cements.

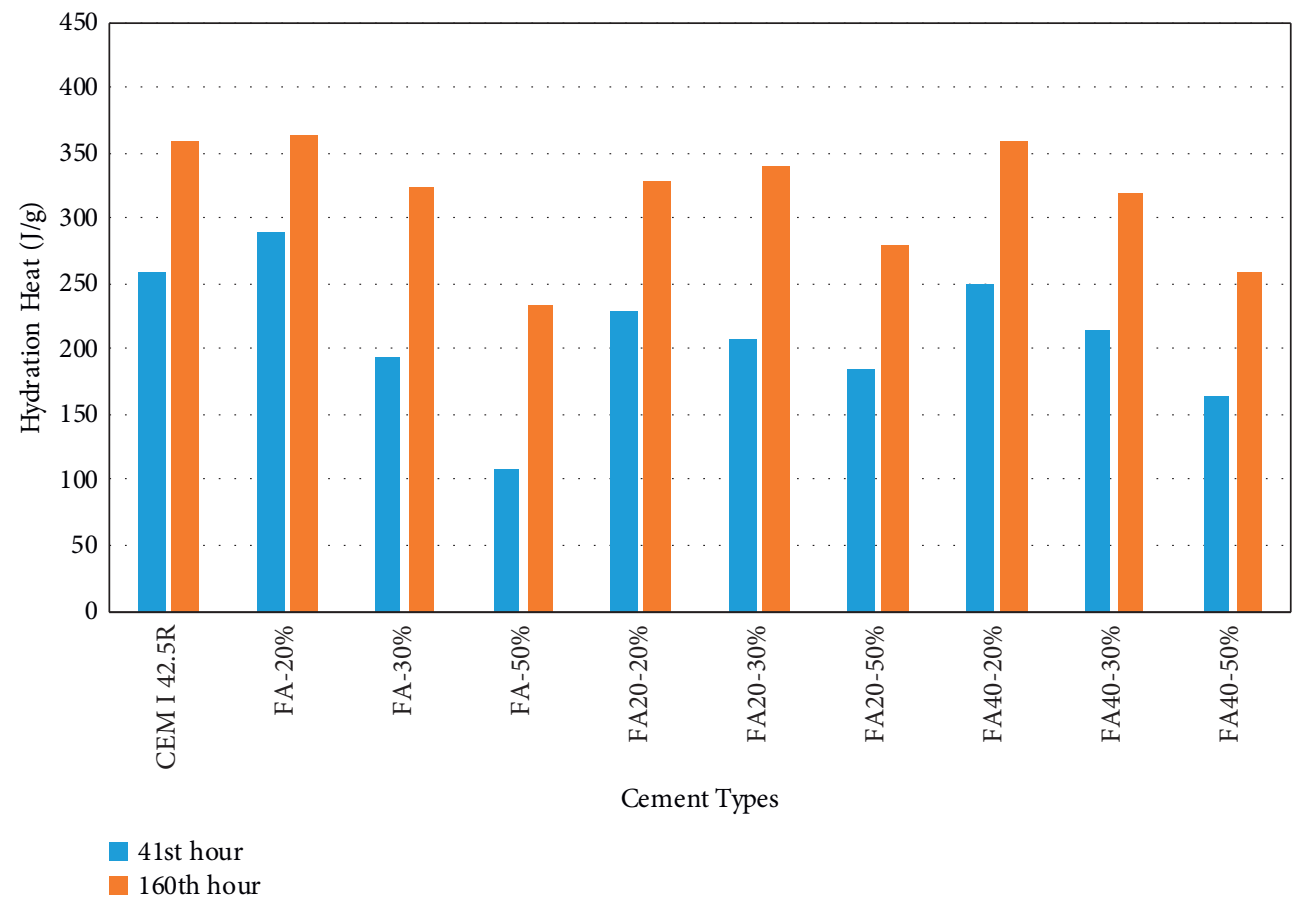

Figure 13: Hydration temperatures at the 41 st and 160th hours in CEM I 42.5R and 20\%, 30\%, and 50\% fly ash cement.

3.5. Effect of Additive Type on Hydration Heat of Blended Cements. Figure 14 shows hydration heat measurements made using the chemical technique, based on TS EN 1968. Since the influence of additive fineness on the hydration heat of cement, as said by TS EN 196-8, was not determined in this study, the hydration temperatures of additive-containing cements are given in Figure 14. The hydration temperatures measured based on TS EN 196-8 are compatible with the values at the 41 st hour based on TS EN 196-9. Han et al. [18] calculated the cement's hydration heat in 80 hours as $300 \mathrm{~J} / \mathrm{g}$; it was $285 \mathrm{~J} / \mathrm{g}$ in $30 \%$ slag contained cement and $180 \mathrm{~J} / \mathrm{g}$ in $35 \%$ fly ash-contained cement [18]. Baran and Pichniarczyk [17] found values ranging from 374 to $404 \mathrm{~J} / \mathrm{g}$ in CEM I 42.5R. The 


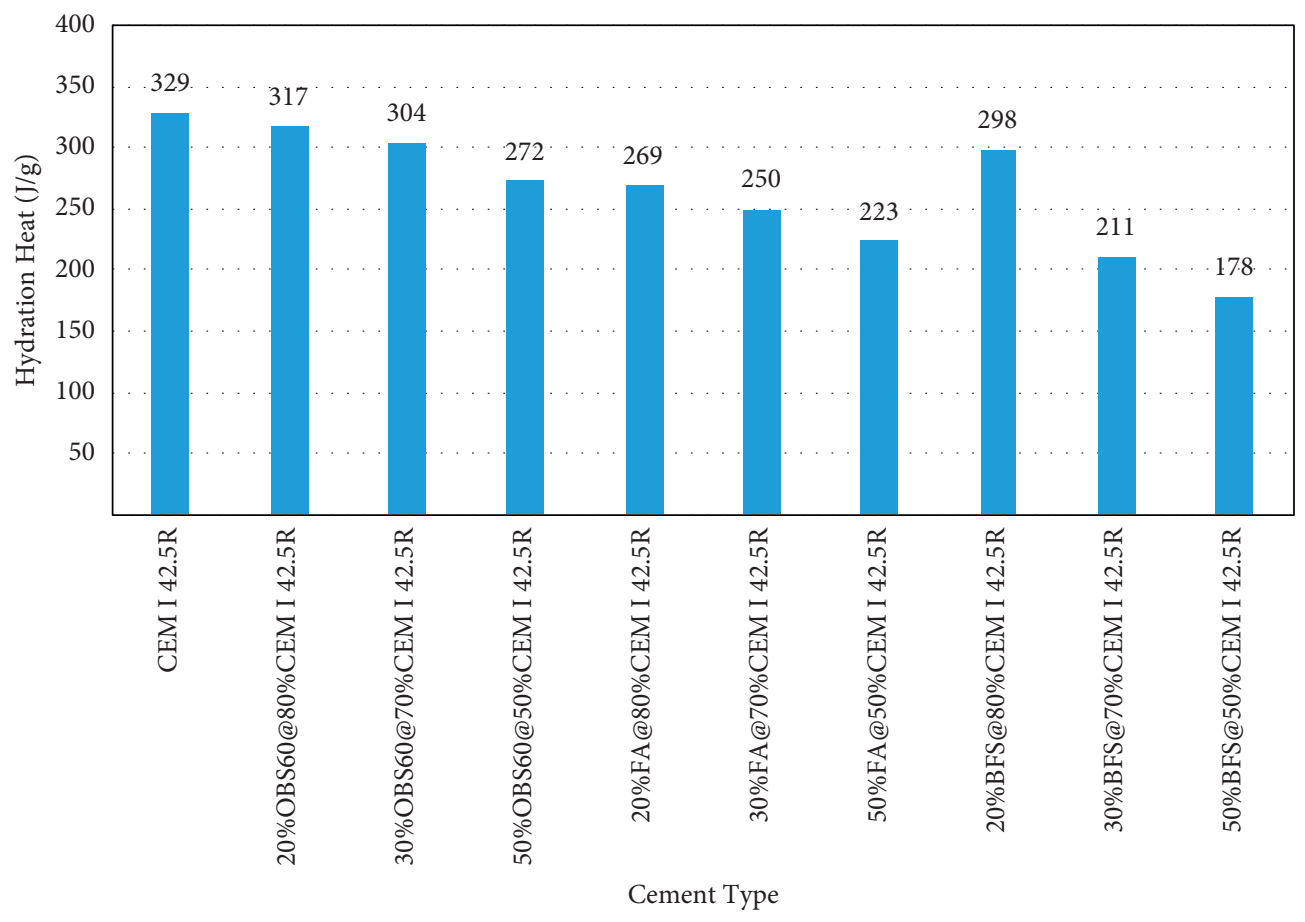

FIGURE 14: Variation of the hydration temperatures measured in the cement.

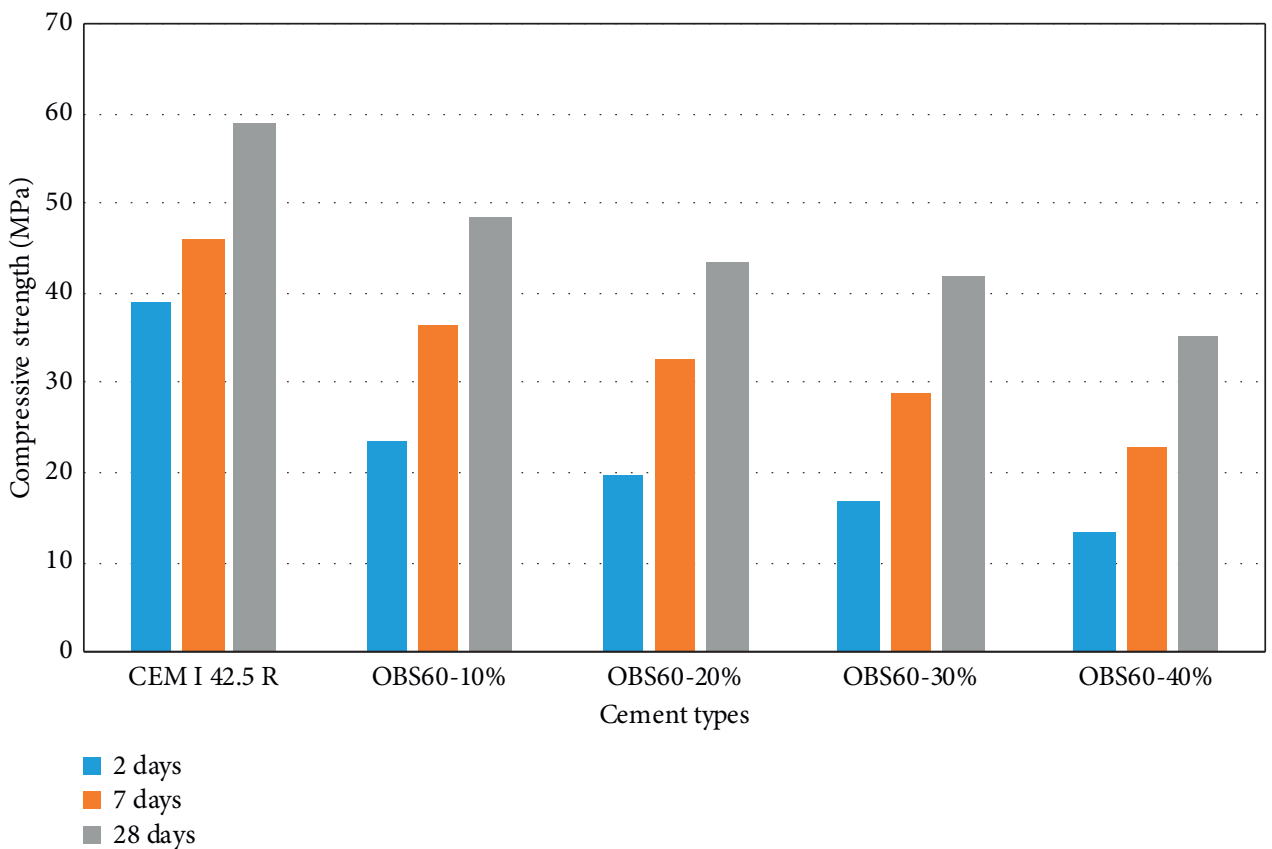

FiguRE 15: Mechanical strength of CEM I 42.5R and mortars produced with 60 -min ground 10\%, 20\%, 30\%, and 40\% obsidian-added cement.

hydration heat of cement was similar to that in the work done by Baran and Pichniarczyk [17]. Merzouki et al. [26] stated that slag's hydration heat falls after $140 \mathrm{~h}$. Adding an additive content of $20 \%$ to cement did not specify a major variation in the hydration heat of obsidian-, fly ash-, and slag-incorporated cements. The hydration heat is strongly affected by the replacement rate of pozzolans and the hydration period.
As the quantity of additives in the mixture rises, the postponement of hydration could set a major drop in the heat of hydration. Cement's hydration heat replaced with $20 \%$ obsidian was akin to that of cements replaced with fly ash and slag additives. The hydration heat was determined using the chemical technique according to TS EN 196-8 to compare the results with those of the tests done according to TS EN 196-9. The determination of hydration heat on 7-day 


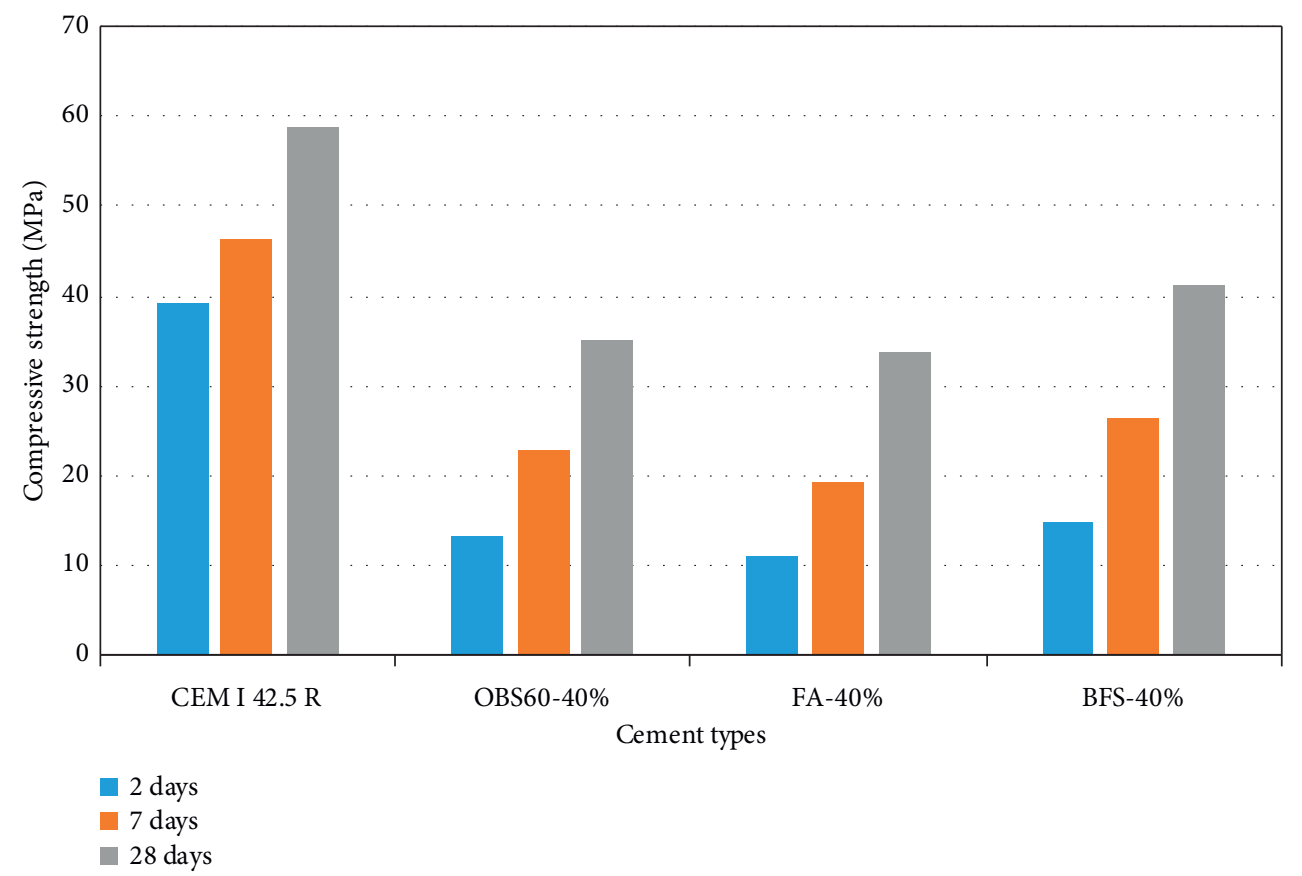

Figure 16: Compressive strengths obtained from CEM I 42.5R cement and cements replaced with obsidian, fly ash, and slag (with a replacement rate of $40 \%$ ) and mortar samples.

cured mortars shows that it corresponds with the hydration heat at the 41st hour [20]. In this study, the hydration temperatures in Figure 14 were found to be close to the values at the 41st hour. The pozzolanic materials used in the cement should not have an adverse impact on the mechanical strength of cement. With the increased replacement rate of fly ash and slag, the corresponding mechanical strength decreases when compared with standard samples.

3.6. Influence of Curing Age on Strength Development of Obsidian-Containing Cements. Figure 15 shows the strengths obtained from CEM I 42.5R and mortar samples prepared as said by TS EN 196-1 with the cement mixed with $10 \%, 20 \%, 30 \%$, and $40 \%$ obsidian for $60 \mathrm{~min}$. As the rate of obsidian additives to cement increases, the corresponding compressive strength decreases.

3.7. Curing Time Effect on Strength Development of AdditiveContaining Cements. Figure 16 shows the strengths obtained from CEM I 42.5R (100\%) and obsidian-, fly ash-, and slag-based cements at a rate of $40 \%$ and mortars prepared as said by TS EN 196-1. The highest strengths were found in CEM I 42.5R, followed by slag-, obsidian-, and fly ash-based cements, respectively.

Obsidian-blended cements behaved similarly to cements replaced with fly ash and slag additives concerning the strength performance as the pozzolan ratio increased. The mechanical strength value of $40 \%$ obsidian-based cement at 2 , 7 , and 28 days was more than that of cement-contained fly ash and lesser than that of cement-contained slag. Khan and Amin [11] found a $22.6 \%$ reduction in the 28 -day strength value of $20 \%$ fly ash-containing cement when compared with the standard sample. The strength value of $40 \%$ fly ash-added cements at 28 days was found to be $42.6 \%$ lower than that of the standard sample. The mechanical strength value of the fly ash-contained cement showed similar effects to the research work done by Khan and Amin [11]. When the mechanical strength values of obsidian and fly ash were compared, it was found that obsidian had a pozzolanic effect in the cement. Schöler et al. [27] demonstrated that the strength value of slag-containing cements is less than that of cement replaced with fly ash when compared with OPC, as seen in this study. This was attributed to the blast furnace slag forming a higher volume of hydration product due to its chemical composition.

\section{Conclusions}

In the present study, the following main conclusions have been drawn:

(i) Accumulation of additives to the unadulterated cement decreases the temperature difference value and the hydration temperature of cement.

(ii) Obsidian additive showed a behavior akin to other additives (fly ash or blast furnace slag) in terms of the impact of cement's hydration temperature.

(iii) Increasing the fineness of the pozzolan up to a certain level causes the highest temperature difference to occur earlier and the hydration temperature to increase. After the pozzolan fineness exceeds a certain value, this relationship cannot be determined clearly.

(iv) There is a tuneful relationship between the hydration heat value calculated by the TS EN 196-9 standard and the value calculated by the TS EN 196-8 method. 


\section{Data Availability}

No data were used to support this study.

\section{Conflicts of Interest}

The authors declare that they have no conflicts of interest.

\section{Acknowledgments}

The authors gratefully thank the Scientific and Technological Research Council of Turkey (TUBITAK, grant no. 214M023) for funding this research.

\section{References}

[1] TS 13515, Complementary Turkish Standard for the Implementation of TS EN 206, Turkish Standard, Ankara, Turkey, 2019.

[2] TS EN 197-1, Cement - Part 1: Composition, Specification and Conformity Criteria for Common Cements, Turkish Standard, Ankara, Turkey, 2012.

[3] I. Ustabas and F. Desik, "Transition coefficients between compressive strengths of samples with different shape and size in mass concrete and use of weight maturity method in dam construction," Structural Concrete, vol. 22, no. 1, pp. 696-709, 2021.

[4] M. K. Ardoga, S. T. Erdogan, and M. Tokyay, "Effect of particle size on early heat evolution of interground natural pozzolan blended cements," Construction and Building Materials, vol. 206, pp. 210-218, 2019.

[5] N. Y. Mostafa and P. W. Brown, "Heat of hydration of high reactive pozzolans in blended cements: isothermal conduction calorimetry," Thermochimica Acta, vol. 435, no. 2, pp. 162-167, 2005.

[6] I. Ustabaş and I. Omur, "The effect of the obsidian of the Rize region on the hydrating heat of cement," Nevsehir Journal of Science and Technology, vol. 8, pp. 78-87, 2019.

[7] S. H. Kosmatka, G. F. Yoigt, and P. Taylor, Integrated Materials and Construction Practices for concrete Pavement: A State-Of-The-Practice Manual, pp. 69-104, Iowa State University, Ames, IA, USA, 2006.

[8] I. Ustabas and A. Kaya, "Comparing the pozzolanic activity properties of obsidian to those of fly ash and blast furnace slag," Construction and Building Materials, vol. 164, pp. 297-307, 2018.

[9] TS25, Natural Pozzolan (Trass) for Use in Cement and concrete - Definitions, Requirements and Conformity Criteria, Turkish Standards, Ankara, Turkey, 2008.

[10] M. Saedi, K. Behfarnia, and H. Soltanian, "The effect of the Blaine fineness on the mechanical properties of the alkaliactivated slag cement," Journal of Building Engineering, vol. 26, Article ID 100897, 2019.

[11] K. Khan and M. N. Amin, "Influence of fineness of volcanic ash and its blends with quarry dust and slag on compressive strength of mortar under different curing temperatures," Construction and Building Materials, vol. 154, pp. 514-528, 2017.

[12] M. I. Khan and A. M. Alhozaimy, "Properties of natural pozzolan and its potential utilization in environmental friendly concrete," Canadian Journal of Civil Engineering, vol. 38, no. 1, pp. 71-78, 2011.

[13] F. Moghaddam, V. Sirivivatnanon, and K. Vessalas, "The effect of fly ash fineness on heat of hydration, microstructure, flow and compressive strength of blended cement pastes," Case Studies in Construction Materials, vol. 10, Article ID e00218, 2019.

[14] Q. Niu, N. Feng, J. Yang, and X. Zheng, "Effect of superfine slag powder on cement properties," Cement and Concrete Research, vol. 32, no. 4, pp. 615-621, 2002.

[15] L. Ting, W. Qiang, and Z. Shiyu, "Effects of ultra-fine ground granulated blast-furnace slag on initial setting time, fluidity and rheological properties of cement pastes," Powder Technology, vol. 345, pp. 54-63, 2019.

[16] H. Binici, O. Aksogan, I. H. Cagatay, M. Tokyay, and E. Emsen, "The effect of particle size distribution on the properties of blended cements incorporating GGBFS and natural pozzolan (NP)," Powder Technology, vol. 177, no. 3, pp. 140-147, 2007.

[17] T. Baran and P. Pichniarczyk, "Correlation factor between heat of hydration and compressive strength of common cement," Construction and Building Materials, vol. 150, pp. 321-332, 2017.

[18] F. Han, X. He, Z. Zhang, and J. Liu, "Hydration heat of slag or fly ash in the composite binder at different temperatures," Thermochimica Acta, vol. 655, pp. 202-210, 2017.

[19] P. Thongsanitgarn, W. Wongkeo, A. Chaipanich, and C. S. Poon, "Heat of hydration of Portland high-calcium fly ash cement incorporating limestone powder: effect of limestone particle size," Construction and Building Materials, vol. 66, pp. 410-417, 2014.

[20] V. Tydlitát, J. Zákoutský, and R. Černý, "Early-stage hydration heat development in blended cements containing natural zeolite studied by isothermal calorimetry," Thermochimica Acta, vol. 582, pp. 53-58, 2014.

[21] S. T. Erdogan and T. Kocak, "Influence of slag fineness on the strength and heat evolution of multiple- clinker blended cements," Construction and Building Materials, vol. 155, pp. 800-810, 2017.

[22] M. K. Saeed, M. K. Rahman, and M. H. Baluch, "Influence of steel and polypropylene fibers on cracking due to heat of hydration in mass concrete structures," Structural Concrete, vol. 20, no. 2, pp. 808-822, 2019.

[23] P. C. Taylor, S. H. Kosmatka, and G. F. Voigt, Integrated Materials and Construction Practices for concrete Pavement: A State-Of-The-Practice Manual, p. 338, National Concrete Pavement Technology Center, Iowa State University, Ames, IA, USA, 2006.

[24] J. W. Bullard, H. M. Jennings, R. A. Livingston et al., "Mechanisms of cement hydration," Cement and Concrete Research, vol. 41, no. 12, pp. 1208-1223, 2011.

[25] M. Demir, T. Erenoglu, H. Ekim, and M. A. Tasdemir, "Effects of fineness and amount of fly ash on strength development of concrete," in Proceedings of the 5th International Congress on Advances in Civil Engineering, pp. 1349-1358, Istanbul, Turkey, September 2002.

[26] T. Merzouki, M. Bouasker, N. E. Houda Khalifa, and P. Mounanga, "Contribution to the modeling of hydration and chemical shrinkage of slag-blended cement at early age," Construction and Building Materials, vol. 44, pp. 368-380, 2013.

[27] A. Schöler, B. Lothenbach, F. Winnefeld, and M. Zajac, "Hydration of quaternary Portland cement blends containing blast-furnace slag, siliceous fly ash and limestone powder," Cement and Concrete Composites, vol. 55, pp. 374-382, 2015.

[28] T. S. En 196-8, Methods of Testing Cement - Part 8: Heat of Hydration - Solution Method, Turkish Standard, Ankara, Turkey, 2011. 